\title{
INVESTIGATING THE IMPLEMENTATION OF CLASSROOM ASSESSMENT BY NOVICE ENGLISH TEACHERS
}

\author{
${ }^{\# 1}$ Karunia Eka Nafilatul Janah, ${ }^{* 2}$ Syafi’ul Anam \\ ${ }^{\# 1}$ English Student, Postgraduate program, Universitas Negeri Surabaya, Indonesia \\ ${ }^{* 2}$ English Lecturer, Postgraduate program, Universitas Negeri Surabaya, Indonesia \\ Corresponding Author Email: karunia.20044@mhs.unesa.ac.id
}

\begin{abstract}
A B S T R A C T S
Classroom assessment plays an important role in the success of English language teaching and learning in the classroom. Besides, implementing classroom assessment can be challenging for teachers since it needs a comprehensive process as well as adequate knowledge related to the subject matter. Some previous studies have proven that Indonesian novice teachers of English faced various challenges related to the real field of teaching that assessment is one of the challenges. Regarding the challenges of the assessment, this research is aimed at investigating the implementation of classroom assessment in assessing students' English skills including its challenges and opportunities faced by novice English teachers. This research employed an open-ended questionnaire involving four female novice English teachers who have less than three years of teaching experience when this research is conducted. The results show that most of the novice English teachers implemented achievement tests that are often summative and used various tasks for assessing their students' English skills. However, some of the novice English teachers could not answer the questions related to their practices of the assessment principles. Furthermore, the novice English teachers experienced challenges in implementing the classroom assessment such as when implementing peer-assessment, creating a valid grade in the assessment process, and not having enough time for the test preparation. Lastly, one of the novice English teachers involved in this research experienced the opportunities related to the implementation of classroom assessment as assessment not only can reflect the students' learning progress, but also can know the weakness of the teaching.
\end{abstract}

\begin{tabular}{l}
\hline A R T I C L E I N F O \\
\hline Article History: \\
Received: June, 2021
\end{tabular}

Revised: October, 2021

Published: December, 2021

\begin{tabular}{l}
\hline Keywords: \\
Classroom Assessment, \\
Novice English Teachers, \\
Students' English Skills, \\
Challenges and \\
Opportunities
\end{tabular}

Keywords:

Classroom Assessment, Novice English Teachers, Challenges and Opportunities

\begin{tabular}{l} 
How to cite: Janah, K., \& Anam, S. (2021). Investigating the Implementation of Classroom Assessment by \\
Novice English Teachers. Jo-ELT (Journal of English Language Teaching) Fakultas Pendidikan Bahasa \& \\
Seni Prodi Pendidikan Bahasa Inggris IKIP, 8(2), 99-108. doi:https://doi.org/10.33394/jo-elt.v8i2.3883 \\
\hline
\end{tabular}

\section{INTRODUCTION}

Assessment plays an important role in language teaching and learning (Cheng \& Fox, 2017) since one way to know whether students can achieve the goals of language teaching and learning is by measuring their language ability or performance, which is through the process of assessment. Assessment can be defined as an ongoing process to measure the language ability, knowledge, or performance of a person or student during the teaching and learning process (Brown, 2004). In other words, assessment is the process of gathering and discussing information from a variety of sources in order to know and understand the knowledge gained by the students from their educational experience and to deepen and improve further learning (Khan, 2018). In addition, whenever students respond to questions, 
offer comments, give opinions, or try out new words, teachers subconsciously do an assessment towards the students' performance. Therefore, assessment cannot be separated from the teaching and learning process since assessment can be a source of information towards students' performance whether the students can successfully achieve the instructional objectives.

Based on the purposes, assessment can be summative, determining students' progress and levels of achievement, or formative, defining the effectiveness of teaching and learning process (Davis, 2018). Summative assessment takes place at the end of the study, while formative assessment is done during the study. Hence, formative assessment is in line with assessment for learning, while summative assessment can be referred to assessment of learning (Cheng \& Fox, 2017). Therefore, since assessment is closely related to learning, assessment should be in line with the learning outcomes stating what the students should know and be able to do at the end of a course that are the results from all of the activities in teaching and learning.

To become a successful language learner, the students are expected to be able to master the four language skills, reading, listening, speaking, and writing (Kurniasih, 2011), as well as to perform their language ability. Hence, the students' ability or performance of these four language skills needs to be measured through the process of assessment in the classroom, which is through classroom assessment. In the classroom assessment, the context of the assessment is in the classroom where the students there are as learners and the teacher is there to engage with the learners in the learning process (Fulcher \& Davidson, 2007). In classroom contexts, tests are a subset of assessments that teachers can use for assessing the students' language ability, but are not the only form of assessment that teachers can make (Brown, 2004). Besides, the results of the tests can give significant effects on the students' language ability, the teachers' performance of teaching, and the language programs or institutions (Douglas, 2014). Therefore, such tests can inform the teachers that the students are making adequate progress and that the teachers themselves are doing their job well.

Designing a classroom language test can be challenging for teachers since it needs a comprehensive process as well as adequate knowledge related to the subject matter. Besides, when it comes to designing English tests, English teachers also have to make sure that they are able to do it well. Meanwhile, not all English teachers are well-experienced in doing such things because of their assessment literacy which can also possibly be related to their length of experience in teaching. Regarding the teachers' length of experience in teaching, a previous research has been conducted by Widiati et al. (2018) that investigated the challenges faced by Indonesian novice teachers of English; those who have completed their language teacher education program and then been commenced teaching English in an educational institution or those who teach a new course for the first time (Farrell, 2012). This research revealed that Indonesian novice teachers of English faced various challenges related to the real field of teaching; one of them is about designing and applying assessment procedures that would be applicable to their classes. In addition, this research also showed that the student evaluation and scoring processes were also demanding since most of the subjects in this research have multiple grades and each class has a large number of students, so a process of student assessment and grading is also required. As a result, novice English teachers recognize the difficulty in assessing students' productive skills (speaking and writing) especially in the development and the implementation of assessment.

As mentioned in the previous paragraph, Indonesian novice teachers of English faced various challenges related to the real field of teaching, then, the result showed that assessment is one of the challenges faced. Regarding the challenges related to assessment faced by novice English teachers, it is necessary to conduct a research that the focus is on the assessment, especially the implementation of classroom assessment by novice English 
teachers including its challenges and opportunities since novice English teachers still have a short duration of teaching experience in English language classroom. As a result, this current research is aimed at investigating the implementation of classroom assessment by novice English teachers in assessing the students' English skills. It also endeavors to reveal the challenges and opportunities that they may experience or face related to the implementation of classroom assessment. Therefore, the research questions can be formulated as follow: 1) how is the implementation of classroom assessment by novice English teachers in assessing the students' English skills?; and 2) how are the challenges and opportunities faced by novice English teachers related to the implementation of classroom assessment in assessing the students' English skills?.

\section{RESEARCH METHOD \\ Research Design}

This research aimed to investigate the implementation of classroom assessment by novice English teachers. The researchers use a case study of qualitative research design. Leavy (2017) stated that qualitative research is often characterized by an inductive approach to knowledge building aimed at producing meaning. In addition, many researchers use this method for a variety of purposes such as to explore, scrutinize, learn about social phenomena, uncover the implications of people for activities, situations, events, or artifacts, and gain insights into specific aspects of social life (Leavy, 2017). In this research, the researchers systematically explore, describe, or explain the implementation of classroom assessment by novice English teachers in assessing the students' English skills in English language classroom. Therefore, it also explores the challenges and opportunities faced by novice English teachers related to the implementation of classroom assessment in assessing the students' English skills.

\section{Population and Subject}

In this research, the data related to the implementation of classroom assessment in assessing students' English skills including its challenges and opportunities were obtained from four female Indonesian novices English teachers. These four novice English teachers participating in this research, then, are named or identified by the researchers as T1, T2, T3, and T4. Besides, the novice English teachers meant in this research refer to the definition of the term 'novice teachers' by Farrell (2012); those who are sometimes called newly qualified teachers. In other words, the term novice teacher in this research means anyone who has just completed pre-service teacher education and has no more than three years of experience in teaching (Widiati et al., 2018). Hence, these four novice English teachers have various durations of teaching experience when this research is conducted; T1 has 2 years of teaching experience, T2 has 1 year and 6 months of teaching experience, T3 has 10 months of teaching experience, and T4 has 2 years and 3 months of teaching experience. Therefore, several openended questions through online questionnaires were given to the subjects as the instruments used to gather the data in this research.

\section{Instruments}

This research employed an open-ended questionnaire given to the four novice English teachers as the instrument used to gather the data in this research. As mentioned previously, there are two research questions which are about the implementation of classroom assessment by novice English teachers and the challenges and opportunities faced by novice English teachers in assessing the students' English skills. Then, for the first research question about the implementation of classroom assessment, four open-ended questions were asked to the 
subjects. Besides, for the second research question, an open-ended question about the challenges and opportunities related to the implementation of classroom assessment was asked. As a result, the data related to the implementation of classroom assessment by novice English teachers including the challenges and opportunities were obtained and then analyzed.

\section{RESEARCH FINDINGS AND DISCUSSION Research Findings}

The first research question is related to the implementation of classroom assessment by the four novice English teachers in assessing their students' English skills. The researchers ask some questions related to classroom assessment and its implementation to the four novice English teachers involved in this research. First, a question on how the four novice English teachers understand assessment in general, was asked. Below are the answers from the four novice English teachers related to their understanding on the assessment in general.

T1: "An instrument to review the outcome of the students' performance. It helps the teacher

to review the students' academic growth to see which part needs improvement."

T2: "Testing or scoring to know how well students have learned."

T3: "Assessing the cognitive, affective, and psychomotor aspects of the students."

T4: "Assessing students to know their learning progress."

As the previous question is about their understanding on the assessment in general, the next question is about how frequent or how many times the four novice English teachers conduct the assessment to their students in English language classroom. Below are the answers from the four novice English teachers.

T1: "I would say that I always assess my students' performance, but for the formal or written assessment I usually do it weekly by accumulating the whole week performance by giving them weekly test."

T2: "I conduct the assessment once at every end of the lesson chapter and also final examination."

T3: "At every end of the lesson chapter, mid-term test, and final test or final examination."

T4: "In the middle of the semester or as the mid-term test."

The next question as part of the first research question is related to the types of assessment tasks for each skill that the four novice English teachers mostly used in assessing their students' skills in English language classroom. Below are the answers from the four novice English teachers related to the types of the assessment tasks.

For reading skill:

T1: "multiple-choice"

T2: "multiple choice and short-answer task"

T3: "used multiple-choice"

T4: "used multiple-choice"

For listening skill:

T1: "multiple-choice and open-ended task"

T2: "cloze-test"

T3: "paragraph completion task and song-lyrics completion task"

T4: "I have not done any assessment yet"

For speaking skill:

T1: "role-play, mini debate, and oral presentation"

T2: "question and answer, conversation, role play, and oral presentation"

T3: "dialogue practice and discussion"

T4: "retelling a story"

For writing skill:

T1: "essay writing" 
T2: "short passage writing or completion test"

T3: "essay or open-ended task"

T4: "writing task like writing a personal letter"

The next question as part of the first research question is about the four novice English teachers' practices of assessment principles for assessing their students' skills in English language classroom; validity, reliability, and practicality. However, some of the novice English teachers could not answer some of the questions. Below are the answers from the four novice English teachers involved in this research.

Validity:

T1: "related to the content which becomes the most considered in measuring the validity of the assessment"

T2: "when the type of the assessment or the test has been matched with the skills that are going to be assessed"

T3: "-"

T4: "I mostly implemented the validity that the questions in the test are in line with the materials taught to the students."

Reliability:

T1: "consistent and dependable"

T2: "I mostly used the test based on reliable module or used the test sheet that has been used for several times, it is like hereditary, so it must be reliable and practical."

T3: "_"”

T4: "_"”

Practicality:

T1: "about the time efficiency of the assessment and when the assessment is relatively easy to administer."

T2: "_"”

T3: "_"”

T4: "_"

The next question as part of the first research question is related to the implementation of the scoring, grading, and feedback by the four novice English teachers in assessing their students' skill. Below are the answers from the four novice English teachers involved in this research.

T1: "It depends on the skill as for writing and speaking I used direct feedback, while for further process I also gave the students the direct feedback in holistic and analytic rubric."

T2: "I rarely used rubrics for scoring, but I just used criterion for grading for a certain score and the feedback for assessment was given indirectly."

T3: "I used the scoring in the form of numbers, and usually gave feedback directly through notes on the test paper if I found students had difficulties in understanding it."

T4: "I was not sure in implementing grading for mid-term test."

The second research question is related to the challenges and opportunities faced by the novice English teachers related to the implementation of classroom assessment in assessing their students' skills. Below are the answers from the four novice English teachers related to the challenges faced in implementing the classroom assessment.

T1: "When it comes to the practice of peer-assessment, students tend to not take it seriously that sometimes it can lead to the bias.

T2: "It is also not easy for the teachers to give a right grade to the students because sometimes the grade does not reflect the students' real competence."

T3: "I do not have a significant obstacle so far." 
T4: "The challenge is on the time that is limited, especially for students who live in the dormitory, that make the students have lack preparation and less time for the test."

Besides, some of the novice English teachers involved in this research could not answer the questions related to the opportunities faced when implementing the classroom assessment. The following is the answer from one of the novice English teachers.

T1: "_"”

T2: "Assessment not only can reflect the students' learning progress, but also can know the weakness of the teaching."

T3: "_."

T4: “_”"

\section{Discussion}

The first research question is related to the implementation of classroom assessment by the four novice English teachers in assessing their students' skills. Based on the findings, T1 answered that assessment is the instrument to review the outcome of the students' performance. In other words, it helps the teacher to review the students' academic progress to see which part needs improvement. Then, T2 answered that assessment is related to testing or scoring to know how well students have learned. In other words, ways to assess the students are through testing and scoring in order to know how well the students have learned during the teaching and learning. Besides, T3 answered that assessment is related to assessing the cognitive, affective, and psychomotor aspects of the students. From this answer, it means that the three domains of cognitive, affective, and psychomotor are taken into consideration in the assessment to know the teaching and learning outputs (Sari \& Rahmah, 2019). Furthermore, T4 answered that assessment is assessing the students in order to know their learning progress. Therefore, based on the answers to the question on how the four novice English teachers understand about assessment in general, it can be seen that all the four novice English teachers have successfully understood and explained assessment in general even though they have less than three years of teaching experience.

The next question as part of the first research question on the implementation of classroom assessment is about how frequent or how many times the four novice English teachers conduct the assessment to their students. Based on the finding, it is found that T1 conducted the assessment weekly or through the weekly test. Then, T2 answered that the assessment is conducted once at every end of the lesson chapter and also the final examination. Next, T3 answered that the assessment is conducted at every end of the lesson chapter, mid-term test, and final test or final examination. Besides, T4 answered that the assessment is conducted in the middle of the semester or as the mid-term test. Therefore, it can be concluded that the four novice English teachers have different ways in implementing the classroom assessment, but most of them implemented the achievement tests that are often summative because they are administered at the end of a unit or term of a study (Brown, 2004).

The next question as part of the first research question is related to the types of assessment tasks for each skill that the four novice English teachers mostly used in the English language classroom. For assessing the students' reading skills, it is found that T1 used multiple-choice, T2 used multiple-choice and short-answer tasks, T3 used multiplechoice, and T4 used multiple-choice. In assessing reading, Brown (2004) mentioned four types of reading performances; perceptive, selective, interactive, and extensive reading. The first type is perceptive reading that involves attending to the components of larger stretches of discourse: letters, words, punctuation, and other symbols with the variety of tasks like reading aloud, written response, multiple-choice, and picture-cued items (Brown, 2004). The second type is selective reading used to measure one's reading recognition of lexical, grammatical, 
or discourse features of language within a very short stretch of language, while the tasks can be multiple choice, picture-cued tasks, matching, true/false, editing, and gap filling. The next type is interactive reading that involves stretches of the language of several paragraphs to one page or more in which the reader should interact with the text, while the focus of the task is to identify relevant features within texts with the objective of retaining the information that is processed (Brown, 2004). The fourth type which is the last type of reading performance is extensive reading which is reading for the purpose of understanding a text. Therefore, it can be seen that the four novice English teachers mostly implemented perceptive and selective reading tasks for assessing the students' reading skills in the English language classroom.

For assessing the students' listening skills, it is found that T1 used the multiple-choice and open-ended task, T2 used cloze-test, T3 used paragraph completion task and song-lyrics completion task, and T4 had not done any assessment yet for assessing the students' listening skills. Besides, for assessing the listening skills, there are four identified types of listening performances; intensive, responsive, selective, and extensive listening. The first involves intensive listening or listening to recognize more important linguistics components (Brown, 2004). The second type is responsive listening or listening to a relatively short language in order to generate a short response; the task is about a response to a question that can be in the form of multiple-choice or open-ended responses. The next type is selective listening or listening to a longer stretches of spoken language to comprehend designated information that the tasks can be listening cloze, information transfer, and sentence repetition. The last type of listening performance is extensive listening or listening to improve the overall understanding of spoken language; the tasks can be dictation, communicative stimulus-response task, and authentic listening tasks, which can be in the form of multiple-choice, short answer, or open-ended answer (Brown, 2004). Therefore, it can be concluded that the four novice English teachers implemented responsive listening and selective listening tasks for assessing the students' listening skills even though one of the novice English teachers had not done any assessment yet for the students' listening skills in English language classroom.

For assessing the students' speaking skills, it is found that T1 used role-play, minidebate, and oral presentation, T2 used question and answer, conversation, role play, and oral presentation, T3 used dialogue practice and discussion, and T4 used retelling a story. Besides, in assessing speaking, there are five identified categories of speaking performances; imitative, intensive, responsive, interactive, and extensive speaking (Brown, 2004). The first category is imitative speaking or the ability to simply imitate a word or phrase or possibly a sentence that the tasks can be repetition tasks. The second category is intensive speaking or the ability to produce a short-range of spoken language to demonstrate competence in a narrow range of grammatical, sentence, lexical or phonetic relationships. The tasks include directed response tasks, reading aloud, sentence and dialogue completion, limited picture cued task, and translation up to the sentence level (Brown, 2004). The third category is responsive speaking which includes interactions and test comprehension but at the limited level of very short conversations, standard greetings and small talks, simple requests and comments, etc. The next category is interactive speaking which has more length and complexity of the interaction than the previous one. This interactive speaking includes multiple exchanges and multiple participants, while the interactions can be in the forms of transactional language or interpersonal exchange like interviews, role-play, discussions and conversations, and games. The last category is extensive speaking or monologue that includes speeches, oral presentations, story-telling, and news event. As a result, it can be seen that the four novice English teachers mostly implemented interactive speaking and extensive speaking tasks for assessing their students' speaking skills in English language classroom. 
For assessing the students' writing skills, it is found that T1 used essay writing, T2 used short passage writing or completion test, T3 used essay or open-ended task, and T4 used writing tasks like writing a personal letter. In assessing writing, there are four categories of writing performances; imitative, intensive (controlled), responsive, and extensive writing (Brown, 2004). The first category is imitative writing involving basic tasks like writing letters, words, punctuation, and very brief sentences. The second category is intensive or controlled writing involving the ability to create context-sensitive vocabulary, idioms, phrases, and create correct grammatical attributes. The next category is responsive writing, in which learners express themselves with a limited level of writing concatenate sentences into single paragraphs, and create logical sequences of two or three paragraphs (Brown, 2004). The last category of writing performance is extensive writing or writing for all purposes such as essays, term papers, project reports, or thesis. Therefore, it can be seen that the four novice English teachers mostly implemented responsive writing and extensive writing tasks for assessing their students' writing skill in English language classroom.

The next question as part of the first research question on the implementation of classroom assessment is about the four novice English teachers' practices of assessment principles for assessing their students' skills in English language classroom; validity, reliability, and practicality. However, some of the novice English teachers could not answer some of the questions. In other words, not all of the novice English teachers involved in this research understand the assessment principles of validity, reliability, and practicality. Then, based on the findings, T1 answered that the validity is related to the content which is most considered in measuring the validity of the assessment. In other words, T1 focused more on the content validity, rather than construct, criterion, and face validity for implementing the classroom assessment in assessing the students' skills. Then, T1 answered that reliability is when it is consistent and dependable, while practicality is about the time efficiency and also when it is relatively easy to administer. Besides, according to T2, validity means that the type of the assessment or the test has been matched with the skills that are going to be assessed that she mostly used the test based on the reliable module or used the test sheet that has been used for several times, it is like hereditary, so it must be reliable and practical. Meanwhile, T3 answered that she mostly implemented the principle of practicality in assessing the students' skills because it is easy to access, the questions are available in paper form, and it is timeefficient as one test includes three skills tested (reading, writing, listening). Besides, T4 answered that she mostly implemented the validity that the questions in the test are in line with the materials taught to the students. Next, for reliability, T1 answered that it is consistent and dependable. Then, for practicality, T1 answered that practicality is about the time efficiency of the assessment and when the assessment is relatively easy to administer. Therefore, related to the assessment principles when implementing the classroom assessment in assessing the students' skills, it can be concluded that some of the novice English teachers involved in this research; focused more on the content validity, rather than construct, criterion, and face validity; used modules and test sheets that have been used for several times so that the results can be consistent and dependable; focused on the time efficiency so that it can be practical.

The next question as part of the first research question is related to the implementation of the scoring, grading, and feedback by the four novice English teachers. T1 answered that it depends on the skill as for writing and speaking, she mostly used direct feedback, and while for further process, T1 also gave the students the direct feedback in the holistic and analytic rubric. Besides, T2 answered that she rarely used rubrics for scoring, but she just used criteria for grading for a certain score. Furthermore, feedback for assessment was given indirectly. Then, T3 used the scoring in the form of numbers, and usually gave feedback directly 
through notes on the test paper. Then, she shared and explained if she found students had difficulties in understanding it. Besides, T4 answered that she was not sure about implementing grading for the mid-term test. In other words, the novice English teacher had difficulties in creating grading and also for students' tests in English language classroom. Hence, the feedback was mostly given in the students' book or as written feedback. Therefore, it can be concluded that the novice English teacher mostly gave direct feedback and also indirect feedback to the students, but had difficulties in creating grading and rubrics for scoring the students' English skills.

The second research question is related to the challenges and opportunities faced by novice English teachers related to the implementation of classroom assessment in assessing their students' English skills. Based on the result, some of the novice English teachers could not answer the questions related to the opportunities faced when implementing the classroom assessment. According to T1, when it comes to the practice of peer-assessment, students tend to not take it seriously that sometimes it can lead to bias. In other words, the novice English teacher experienced a challenge in implementing the peer-assessment in English language classroom. Another challenge in assessing the students' skills is that it is not easy for novice English teachers to give a right grade to the students because sometimes the grade does not reflect the students' real competence. In other words, creating a valid grade in the assessment process is not easy for novice English teachers. Then, T3 answered that she does not have a significant obstacle so far. Furthermore, T4 stated that the challenge is on the limited time, especially for students who live in the dormitory, which make the students have lack preparation and less time for the test. Besides, the opportunity faced by the novice English teacher is found in T2's answer as she stated that assessment not only can reflect the students' learning progress, but also can know the weakness of the teaching. In other words, the results of the tests can give significant effects on the students' language ability, the teachers' performance of teaching, and the language programs or institutions (Douglas, 2014). Therefore, the results of the classroom assessment can be the evidence of the students' language learning so that the teachers know whether the teaching and learning are successful and whether any students may need additional support or help in their educational experiences.

\section{CONCLUSION}

This research is aimed at investigating the implementation of classroom assessment by novice English teachers in assessing the students' English skills. It also endeavors to reveal the challenges and opportunities that they may experience or face related to the implementation of classroom assessment in assessing the students' English skills. Based on the result of this research, the researchers state several points. First, all the novice English teachers have successfully understood and explained assessment in general even though they have less than three years of teaching experience. Second, novice English teachers have different ways in implementing the classroom assessment, but most of them implemented the achievement tests that are often summative because they are administered at the end of a unit or term of a study. Third, for assessing the students' reading skills, the novice English teachers mostly implemented perceptive and selective reading tasks in English language classroom. Fourth, the novice English teachers implemented responsive listening and selective listening tasks for assessing the students' listening skills in English language classrooms. Fifth, the novice English teachers mostly implemented interactive speaking and extensive speaking tasks for assessing their students' speaking skills in English language classrooms. Sixth, the novice English teachers mostly implemented responsive writing and extensive writing tasks for assessing their students' writing skills in English language classroom. Seventh, the novice English teachers mostly implemented interactive speaking 
and extensive speaking tasks for assessing their students' speaking skills in English language classrooms. Eighth, related to the practices of the assessment principles for the classroom assessment, although some of the novice English teachers involved in this research could not answer some of the questions related to the assessment principles of validity, reliability, and practicality, it is found that they focused more on the content validity, rather than construct, criterion, and face validity; used modules and test sheets that have been used for several times so that the results can be consistent and dependable; focused on the time efficiency so that it can be practical. Ninth, the novice English teachers mostly gave direct feedback and also indirect feedback to the students, but had difficulties in creating grading and rubrics for scoring the students' English skills. Tenth, the novice English teachers experienced some challenges in the implementation of classroom assessment for assessing their students' English skills such as challenges in implementing the peer-assessment for assessing their students' skills, creating a valid grade in the assessment process, and from the students' side that is not having enough time for the test preparation. Last but not least, one of the novice English teachers involved in this research experienced the opportunities related to the implementation of classroom assessment in assessing the students' English skills as assessment not only can reflect the students' learning progress, but also can know the weakness of the teaching.

\section{REFERENCES}

Brown, H. D. (2004). Language Assessment: Principles and Classroom Practices. Longman. Cheng, L., \& Fox, J. (2017). Assessment in the Language Classroom. Palgrave.

Davis, J. M. (2018). Terminology: Assessment, Evaluation, and Testing. In The TESOL Encyclopedia of English Language Teaching. John Wiley \& Sons, Inc. https://doi.org/10.1002/9781118784235.eelt0341

Douglas, D. (2014). Understanding Language Testing. Routledge.

Farrell, T. S. C. (2012). Novice-Service Language Teacher Development: Bridging the Gap Between Preservice and In-Service Education and Development. TESOL Quarterly, 46(3), 435-449. https://doi.org/10.1002/tesq.36

Fulcher, G., \& Davidson, F. (2007). Language Testing and Assessment. Routledge.

Khan, R. (2018). What Is Assessment? Purposes of Assessment and Evaluation. In The TESOL Encyclopedia of English Language Teaching. John Wiley \& Sons, Inc. https://doi.org/10.1002/9781118784235.eelt0340

Kurniasih, E. (2011). Teaching the Four Language Skills in Primary EFL Classroom. JET (Journal of English Teaching), 1(1), 70. https://doi.org/10.33541/jet.v1i1.53

Leavy, P. (2017). Research Design Quantitative, Qualitative, Mixed methods, Arts-based and Community-based Participatory Research Approaches. The Guilford Press.

Sari, I. D. P., \& Rahmah, T. H. (2019). Virtual Discussion for EFL Students Establishing Three Domains: Cognitive, Affective, and Psychomotor. International Journal for Educational and Vocational Studies, 1(3), 249-253. https://doi.org/10.29103/ijevs.v1i3.1586

Widiati, U., Suryati, N., \& Hayati, N. (2018). Unraveling the challenges of Indonesian novice teachers of English. Indonesian Journal of Applied Linguistics, 7(3), 621-629. https://doi.org/10.17509/ijal.v7i3.9824 